\title{
Oligomerization of fatty acids as a possible source for high molecular weight hydrocarbons and sulphur-containing compounds in sediments
}

\author{
J. C. DeL Rio* and R. P. PHILP \\ School of Geology and Geophysics, The University of Oklahoma, Energy Center Building, \\ 100-E. Boyd Street, Norman, OK 73019, U.S.A.
}

(Received 23 October 1991; accepted in revised form 11 May 1992)

\begin{abstract}
In an attempt to understand some of the possible mechanisms for the formation of high molecular weight hydrocarbons present in oils and source rocks, artificial maturation experiments have been performed with naturally-occurring fatty acids $\left(\mathrm{C}_{16}-\mathrm{C}_{26}\right)$ both in the presence and absence of the clay mineral bentonite and elemental sulphur. The heating experiments, performed at $300^{\circ} \mathrm{C}$ for $168 \mathrm{~h}$, resulted in the formation of complex mixtures of high molecular weight hydrocarbons $\left(>\mathrm{C}_{40}\right)$ and organic sulphur compounds, comprising mainly di- and trimerization products of the original fatty acids. In the presence of bentonite, and absence of elemental sulphur, relatively high proportions of di- and trimerization products were obtained with the total amounts of saturate hydrocarbons recovered being $30-40 \%$ of the weight of the original fatty acid. The presence of elemental sulphur in the reaction mixtures leads to preferential decarboxylation and little if any oligomerization. Furthermore the presence of elemental sulphur leads to the formation of series of 2,5-dialkylthiophenes and 2,4-di- $n$-alkylbenzo(b)thiophenes. The high molecular weight compounds produced in these experiments were analysed by high temperature gas chromatography (HTGC), direct insertion probe-mass spectrometry (DIP-MS) and, in selected cases, gas chromatography-mass spectrometry (GC-MS). In this paper, the results of these investigations are discussed in terms of the possible origin of the high molecular weight hydrocarbons and organic sulphur compounds recently isolated from different geological materials.
\end{abstract}

Key words - high molecular weight hydrocarbons, high temperature gas chromatography (HTGC), fatty acids, organic sulphur compounds

\section{INTRODUCTION}

The occurrence of high molecular weight hydrocarbons $\left(>\mathrm{C}_{40}\right.$; HMWHC) in geological materials has received little attention until relatively recently due to the analytical difficulties of using conventional gas chromatographic columns. Albaiges (1980) and Moldowan et al. (1983), respectively, presented data on the occurrence of extended series of acyclic isoprenoids and tricyclic terpanes, beyond $\mathrm{C}_{40}$. Recently, van Aarssen and de Leeuw (1989) identified some $\mathrm{C}_{45}$ hydrocarbons, thought to be trimeric cadinanes in several oils from South East Asia. Kohnen et al., (1990a), using high temperature gas chromatography (HTGC), reported the occurrence of a series of high molecular weight thiophenes $\left(\mathrm{C}_{36}-\mathrm{C}_{54}\right)$ with an unusual skeleton in several crude oils. Carlson et al. (1989) and Del Rio and Philp (1992a), also using HTGC, reported the occurrence of HMWHC up to $\mathrm{C}_{75}$ in solid bitumens, crude oils, and waxes.

Several hypotheses have been proposed already for the occurrence of these HMWHC in geological ma-

*Permanent address: Instituto de Recursos Naturales y Agrobiologia de Sevilla, C.S.I.C., P.O. Box 1052, 41080Seville, Spain. terials (Del Rio and Philp, 1992b). The hydrocarbons may be derived directly from high molecular weight precursors present in living organisms, such as carotenoids up to $\mathrm{C}_{50}$ (Liaeen-Jensen, 1990) and polyisoprenyl alcohols up to $\mathrm{C}_{100}$ and above (Chojnacki et al., 1987; Swiezewska and Chojnacki, 1988, 1989; Suga et al., 1989). Various polyprenols have been suggested as possible precursors for high molecular weight isoprenoids (Albaiges, 1980) and tricyclic terprenoids (Moldowan et al., 1983) above $\mathrm{C}_{40}$. Kohnen et al. (1990a), have suggested that high molecular weight mid-chain dimethyl branched hydrocarbons with two methylenic double bonds are possible precursors for the series of 3,4-dialkylthiophenes detected in the range $\mathrm{C}_{36}-\mathrm{C}_{54}$, although no natural products have been reported so far from organisms and/or sediments having such a carbon skeleton. HMWHC may be formed by decomposition of asphaltenes at high temperatures and/or pressures as suggested by Del Rio and Philp (1992a), following the analysis of a series of asphaltenes by flash pyrolysis and artificial maturation experiments in which $\mathrm{HMWHC}$ up to $\mathrm{C}_{75}$ were produced from the asphaltenes. Finally, HMWHC may be formed by oligomerization of lower molecular weight precursors. De Leeuw et al., (1980) obtained an aromatic dimerization product following the heating of phytol in the 
presence of clay minerals and the formation of some trimerization products. Rubinstein and Strausz (1979) reported the formation of some dimerization products by heating fatty acids in the presence of clay minerals. The $\mathrm{C}_{45}$ tricadinane hydrocarbons identified in crude oils from South East Asia (van Aarssen and de Leeuw, 1989), may be considered as trimerization products of cadinane monomers.

In order to assess the feasibility of this last hypothesis, namely oligomerization, a number of artificial maturation experiments using closed tube pyrolysis reactions and naturally occurring fatty acids have been performed in the presence of bentonite and, in some cases, elemental sulphur. The products obtained from these experiments have been analyzed by high temperature gas chromatography (HTGC), and direct insertion probe-mass spectrometry (DIP-MS), and where appropriate HTGC-MS.

\section{EXPERIMENTAL}

\section{Closed system maturation experiments}

The maturation experiments were carried out under conditions similar to those described by Rubinstein and Strausz (1979). A series of saturated fatty acids ranging from $\mathrm{C}_{16}$ to $\mathrm{C}_{26}$ (100-200 mg; Aldrich), were intimately mixed with bentonite $(200-600 \mathrm{mg}$ ) (Clay Spur, Wyoming) and sealed in glass tubes under 0.1 torr pressure. The tubes were heated at $300^{\circ} \mathrm{C}$ for $168 \mathrm{~h}$, after which their contents were exhaustively extracted with dichloromethane by sonication. The products were evaporated to dryness, weighed and subsequently separated into saturate, aromatic, and polar fractions by alumina column chromatography. Unreacted fatty acids eluted in the aromatic fraction and were removed by precipitation. Blank experiments were also performed using fatty acids alone. In additional experiments, selected fatty acids were heated in the presence of elemental sulphur $(60 \mathrm{mg})$, with and without bentonite, using the experimental conditions described above. Quantitative data from the experiments with the $C_{20}$ and $C_{26}$ fatty acids are reported in terms of percentages of the weight of the initial fatty acid in Table 1.

High temperature gas chromatography (HTGC). The saturate and aromatic fractions were analyzed with a Carlo Erba gas chromatograph equipped with an aluminum-coated fused silica column ( $25 \mathrm{~m} \times 0.35 \mathrm{~mm}$ i.d.) capable of withstanding GC temperatures up to $450^{\circ} \mathrm{C}$. The detector and injector were set at $400^{\circ} \mathrm{C}$ and the oven was temperature programmed from 80 to $440^{\circ} \mathrm{C}$ at a rate of $8^{\circ} \mathrm{C} / \mathrm{min}$ with $50 \mathrm{~min}$ final hold time. The samples were dissolved in warm $p$-xylene before injection. The polar fractions were not further analyzed in these experiments.

Gas chromatography-mass spectrometry (GC-MS). GC-MS analyses were performed with a Finnigan TSQ 70 mass spectrometer equipped with a DB-5 fused silica capillary column and using $\mathrm{He}$ as carrier gas. The oven was programmed from 60 to $320^{\circ} \mathrm{C}$ at a rate of $2^{\circ} \mathrm{C} / \mathrm{min}$, and the injector and transfer line temperatures were set at $310^{\circ} \mathrm{C}$. The mass spectrometer was operated in the electron impact (EI) mode at $70 \mathrm{eV}$ ion source energy.

Direct insertion probe-mass spectrometry (DIP$M S$ ). DIP-MS analyses were performed with a Finnigan Triple Stage Quadrupole (TSQ 70) mass spectrometer. The probe was temperature programmed from 60 to $320^{\circ} \mathrm{C}$ at a rate of $50^{\circ} \mathrm{C} / \mathrm{min}$, and held for $2 \mathrm{~min}$ at $320^{\circ} \mathrm{C}$. The mass spectrometer was operated in the electron impact (EI) mode at $70 \mathrm{eV}$ ion source energy.

\section{RESULTS AND DISCUSSION}

The presence of high molecular weight hydrocarbons (above $C_{40}$ ) ranging up to $C_{75}$ and even higher, has been reported recently in some solid bitumens and crude oils (van Aarssen and de Leeuw, 1989; Carlson et al., 1989; Del Rio and Philp, 1992a). In some cases, the HMWHC discovered could be regarded as the result of oligomerization of lower molecular weight precursors on the basis of structural similarities (van Aarssen and de Leeuw, 1989), Rubinstein and Strausz (1979) and de Leeuw et al. (1980) obtained several di- and trimerization products from simulation experiments with fatty acids and phytol respectively; it is proposed that similar processes may be responsible for at least some of the high molecular weight compounds $\left(>\mathrm{C}_{40}\right)$ detected in geological materials. Artificial maturation experiments in the presence of clay mineral catalysts have been shown to be a valid simulation for the natural diagenetic process involved in the formation of geochemical markers, in the low molecular weight region $\left(<\mathrm{C}_{40}\right)$, from biological materials. For example the thermal decomposition of fatty acids in the presence of clay minerals has been studied by several investigators (Johns, 1979; Aizenshtat et al., 1984). They proposed decarboxylation of fatty acids to hydrocarbons, catalysed by clay minerals, as a possible pathway for the conversion of lipids into petroleum hydrocarbons.

Table 1. Relative quantitation data for experiments performed in presence of bentonite and elemental sulphur

\begin{tabular}{lcccccc}
\hline Reaction mixture & Saturates & Aromatics & NSO (1) & NSO (2) & Unreacted & Unrecovered \\
\hline$C_{20}$ FA/bentonite & 38.6 & 5.1 & 0.7 & - & 8.5 & 47.1 \\
$\mathrm{C}_{26} \mathrm{FA} /$ bentonite & 33.6 & 4.8 & 0.9 & - & 4.7 & 56 \\
$\mathrm{C}_{16} \mathrm{FA} /$ bentonite $/ \mathrm{S}^{\circ}$ & 44.3 & 4.8 & 3.0 & 9.3 & - & 38.6 \\
$\mathrm{C}_{16} \mathrm{FA} / \mathrm{S}^{\circ}$ & 52.6 & 3.8 & 3.0 & 13.8 & - & 29.8 \\
\hline
\end{tabular}


(a) Simulation experiments with fatty acids in the presence of bentonite

The chromatogram of the saturated hydrocarbon fraction isolated after a maturation experiment performed with the $\mathrm{C}_{16}$ fatty acid, palmitic acid, in the presence of bentonite is shown in Fig. 1(a). The experiment resulted in the formation of a relatively high proportion of hydrocarbons in the high molecular weight region of the chromatogram. Two distinct groups of compounds can be distinguished in the high molecular weight region of this chromatogram corresponding to di- and trimerization products of the $\mathrm{C}_{16}$ fatty acid. A similar observation can be made from Figs 1(b) and (c) showing the hydrocarbon products obtained from maturation experiments using the $C_{20}$ and $\mathrm{C}_{26}$ fatty acids respectively. However with the $\mathrm{C}_{26}$ fatty acid, no trimerization products could be detected in chromatogram probably as a result of difficulties both with extraction and elution from the GC column even at high temperatures. The quantitation data obtained from the $\mathrm{C}_{20}$ and $\mathrm{C}_{26}$ fatty acid reactions in the presence of bentonite are summarized in Table 1. These results are expressed as percentages of the weight of the original fatty acid. The overall yields were approx. $50 \%$ with the remaining material assumed to be gaseous products or intractable material. In a maturation experiment with a mixture of $\mathrm{C}_{16}, \mathrm{C}_{18}$ and $\mathrm{C}_{20}$ fatty acids more complex mixtures of HMWHC were formed as a result of the various possible combinations of the different fatty acid monomers [Fig. 1(d)].

The saturate products isolated from the maturation experiments with palmitic acid $\left(\mathrm{C}_{16}\right)$ were analyzed by GC-MS and the compounds in the low molecular weight region of the chromatogram in Fig. 1(a) were found to be similar to those previously reported by Rubinstein and Strauss (1979). Products of decarboxylation, such as $n$-pentadecane $\left(\mathrm{C}_{15}\right)$ and branched isomers, and several other normal and branched alkanes were the major components in this region of the chromatogram. $n$-Dodecylcyclohexane, and the three isomers of methyl- $n$-undecylcyclohexane, were found to be present as reported previously by Rubinstein and Strausz (1979) in similar experiments using stearic and oleic acids as starting materials. According to these authors, the cyclic compounds may have been formed directly from an intermediate in which the carboxyl group was chemically bound to the clay mineral structure with cyclization being concommitant with the release of the molecule from the clay mineral.

In the high molecular weight region, several compounds were found in relatively high concentration, corresponding to di- and trimerization products. The dimerization products consisted mainly of $\mathrm{C}_{31}$ compounds, with minor amounts of $\mathrm{C}_{29}, \mathrm{C}_{30}$ and $\mathrm{C}_{32}$ compounds, whereas the trimerization structures were mainly $\mathrm{C}_{46}$ compounds with minor amounts of $\mathrm{C}_{47}$ and $\mathrm{C}_{48}$ compounds. Different classes of $\mathrm{C}_{31}$ and
$\mathrm{C}_{46}$ compounds were detected, corresponding to: (1) saturated alkanes $\left(\mathrm{C}_{31} \mathrm{H}_{64} \mathrm{MW} 436 ; \mathrm{C}_{46} \mathrm{H}_{94} \mathrm{MW}\right.$ 646); (2) compounds with one degree of unsaturation (cyclic or double bond); $\left(\mathrm{C}_{31} \mathrm{H}_{62} \mathrm{MW} 434 ; \mathrm{C}_{46} \mathrm{H}_{92}\right.$ MW 644); and (3) aromatic hydrocarbons $\left(\mathrm{C}_{31} \mathrm{H}_{56}\right.$ MW 428; $\mathrm{C}_{46} \mathrm{H}_{86} \mathrm{MS}$ 638). The precise identification of individual compounds was hampered due to the presence of several isomers at each carbon number although a number of tentative interpretations could be made.

The dimerization products appear to be formed by various combinations of $\mathrm{C}_{15}$ and $\mathrm{C}_{16}$ moieties. The presence of a prominent fragment at $m / z 238$ in the mass spectra of many of these compounds suggests the presence of a $n$-pentadecyl group attached to the rest of the molecule. This structure seems to be present in several of the dimerization products on the basis of the mass spectral data as can be seen from the mass spectrum of one of the $\mathrm{C}_{31}$ saturated hydrocarbons shown in Fig. 2(a). The fragment ions at $\mathrm{m} / \mathrm{z}$ $210,224,238$ and 252 suggest that the compound producing this spectrum could be either a mid-chain dimethyl alkane or a mixture of two monomethyl alkane isomers of the type shown in Fig. 3, any of which could arise from the dimerization of $\mathrm{C}_{15}$ and $\mathrm{C}_{16}$ moieties. Several isomers of an unsaturated compound with a molecular weight of 434 were also detected and although it was not always possible to distinguish between the presence of a double bond or ring structure from their mass spectra, both types of compounds would appear to be present. The mass spectrum of the $\mathrm{C}_{31}$ hydrocarbon in Fig. 2(b) shows a prominent fragment ion at $m / z 97$ and a series of peaks at $m / z 97+14 n$, suggesting a cyclic structure substituted with aliphatic chains. Long-chain dialkylcyclohexanes are characterized from their mass spectra by the presence of even-numbered fragments, at $\mathrm{C}_{n} \mathrm{H}_{2 n-2}$, due to a hydrogen transfer from the ring to one of the side chains which is cleaved subsequently to produce a neutral moeity. The most prominent ion in this series of $\mathrm{C}_{n} \mathrm{H}_{2 n-2}$ fragment ions is at $m / 2222$ which suggests that one of the substituents in the compound producing the spectrum in Fig. 2(b) is an $n$-decyl chain attached to the cyclohexane ring. If correct, the other substituent would be a $n$-pentadecyl chain producing a dialkylcyclohexane. Another compound, with similar mass spectrum, was also detected and thought to be a positional isomer of the compound producing the spectrum of Fig. 2(b) although the position of substitution could not be determined. From this mass spectral data it is clear that the $\mathrm{C}_{16}$ moiety is the one that cyclizes whilst the $\mathrm{C}_{15}$ structure is attached to the ring. It is known that long chain alkyl groups can be attached to cyclohexane rings as a result of alkylation via free radical reactions (Williams et al., 1988). The $\mathrm{C}_{16}$ alkylcyclohexanes produced in these maturation experiments, and previously reported by Rubinstein and Strausz (1979), probably have been alkylated by the $C_{15}$ long-chain alkyl radical, formed after decarboxyla- 


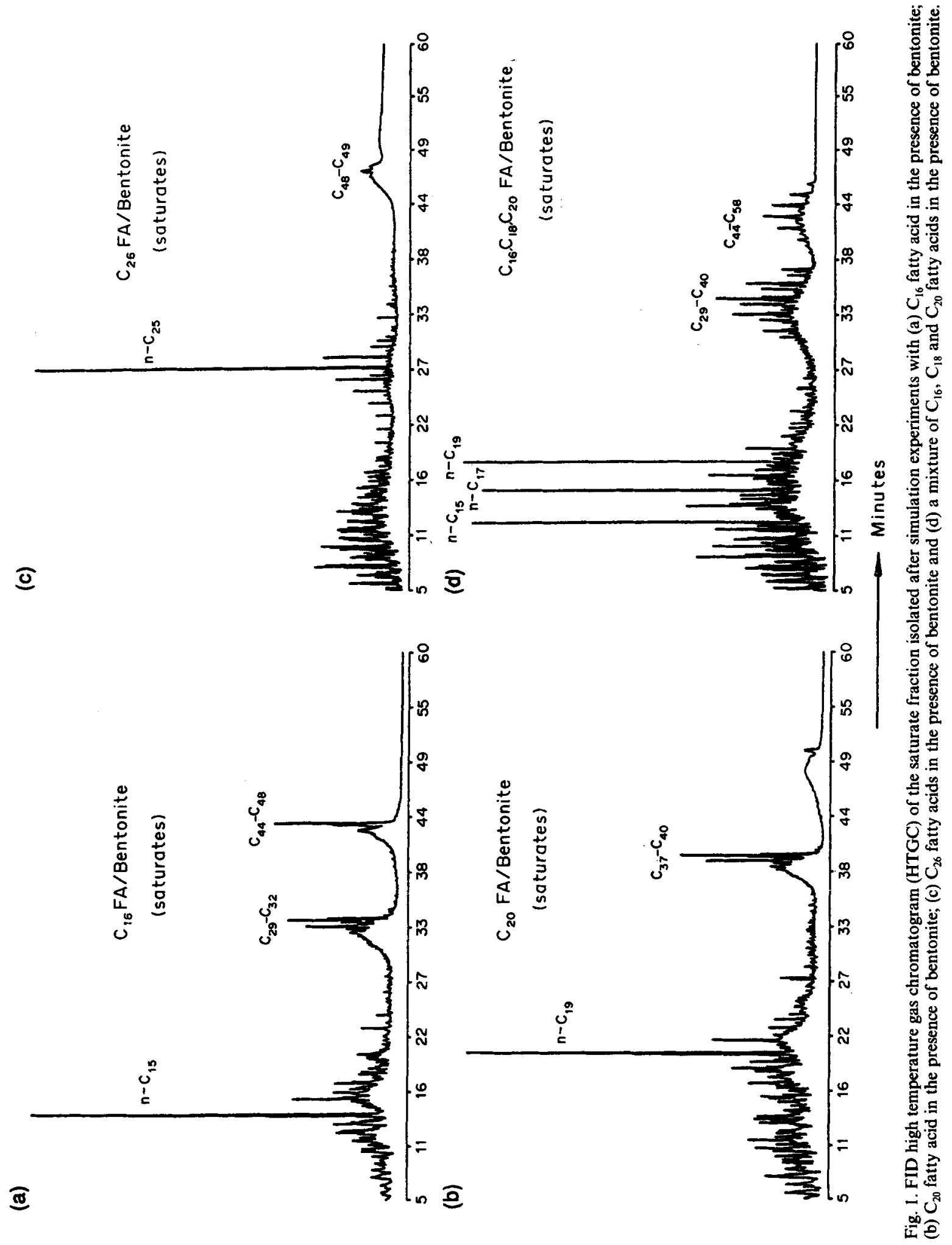




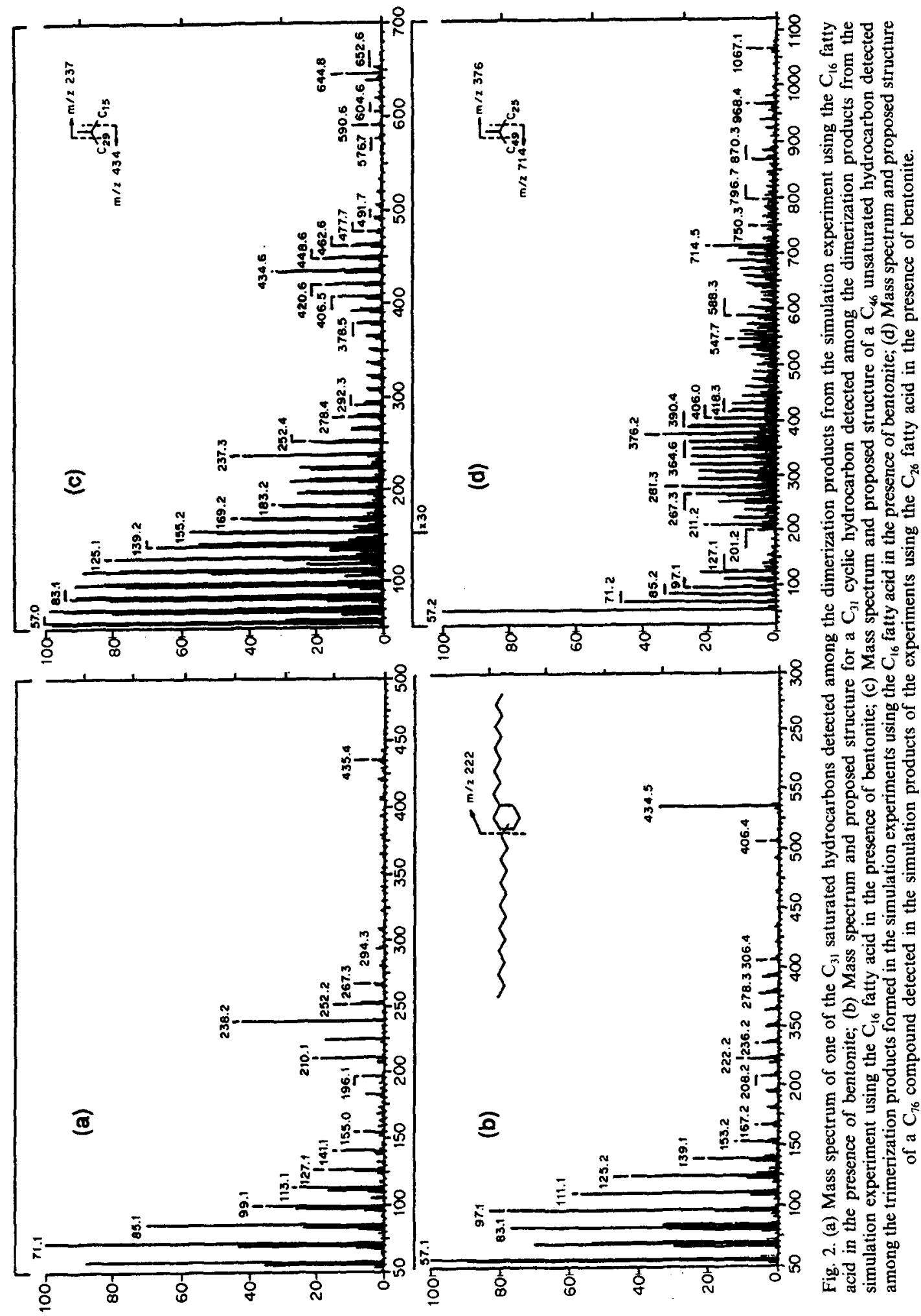



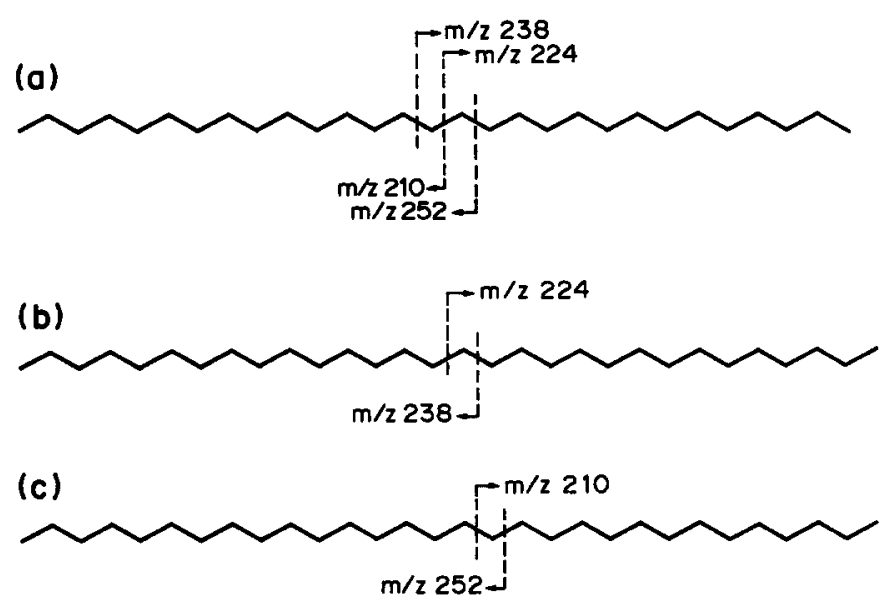

Fig. 3. Structures of various $C_{31}$ hydrocarbons referred in the text.

tion of the fatty acid, to form dialkylcyclohexane hydrocarbons. In a previous paper, Del Rio and Philp (1992a) reported a series of long-chain dialkylcyclohexanes with carbon numbers ranging up to $C_{80}$, as major compounds in the branched/cyclic saturated fraction isolated from a solid bitumen ozocerite and it was proposed that these compounds were formed by the condensation of fatty acids as described above. Several isomers of $\mathrm{C}_{31}$ aromatic compounds were also detected by monitoring the ion at $m / z 428$, corresponding to dialkylbenzenes formed by subsequent dehydrogenation of the dialkylcyclohexanes.

The mass spectrum of an unsaturated $\mathrm{C}_{46}$ compound, formed by the combination of two $\mathrm{C}_{15}$ and one $\mathrm{C}_{16}$ moieties is shown in Fig. 2(c). The fragment at $m / z 434$ suggests branching at the C-30 carbon position of a saturated chain, while the fragments at $m / z 236,237$ suggests an unsaturated chain attached to the branch although it was not possible to determine whether the unsaturation corresponded to a double bond or cyclization. Several $\mathrm{C}_{46}$ unsaturated isomers with similar mass spectra were found and a series of $\mathrm{C}_{46}$ aromatic compounds was also detected.

The analysis by DIP-MS of the products formed after the simulation experiments with the $\mathrm{C}_{20}, \mathrm{C}_{22}$ and $\mathrm{C}_{26}$ fatty acids also showed the formation of $\mathrm{C}_{2 n-1}$ dimerization and $\mathrm{C}_{3 n-2}$ trimerization products, as in the case of the $C_{16}$ fatty acid. These compounds were totally saturated $\left(\mathrm{C}_{39} \mathrm{H}_{80} \mathrm{MW} \mathrm{548;} \mathrm{C}_{43} \mathrm{H}_{88} \mathrm{MW} \mathrm{604;}\right.$ $\mathrm{C}_{51} \mathrm{H}_{104} \mathrm{MW}$ 716), had one degree of unsaturation

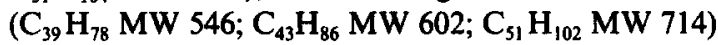
or were aromatic hydrocarbons $\left(\mathrm{C}_{39} \mathrm{H}_{78} \mathrm{MW}\right.$ 540;

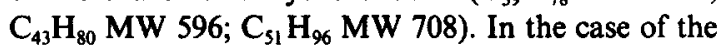
$\mathrm{C}_{26}$ fatty acid, a trimerization product having 76 carbon atoms was found that had not been detected previously in the HTGC trace. The mass spectrum of this compound [shown in Fig. 2(d)] contains characteristic fragments at $m / z 376$ and 714 , suggesting a structure like that shown in Fig. 2(d), with an unsaturation in the $\mathrm{C}_{25}$ side chain. The nominal molecular weight of an unsaturated compound with this struc- ture is 1064 . A mixture with a $\mathrm{C}_{76}$ totally saturated hydrocarbon is apparent since there is also a molecular ion at $m / z \quad 1067$, corresponding to a nominal molecular weight of 1066, and a series of even-numbered fragments at $m / z 364+14 n$ is also present.

Series of $n$-alkyl and di- $n$-alkylnaphthalenes were present in the aromatic fractions of the maturation reactions, ranging from $C_{10}$ (naphthalene) to $C_{31}$, with several isomers being present at each carbon number. It has been suggested previously that aromatization of non-aromatic cyclic biological precursors could be one of the main sources of alkylaromatic compounds in sediment extracts (Radke et al., 1982). From the results presented herein it is proposed that acyclic biological precursors (i.e. fatty acids) can also produce aromatic hydrocarbons via various cyclization and aromatization mechanisms. Rigby et al., (1986) have also demonstrated that, in the presence of clay minerals alkylaromatic hydrocarbons may be formed from the interaction of simple aromatic compounds and naturally occurring alcohols or esters or alkenes added to the reaction mixtures. The results of these various experiments raise the possibility that some of the alkylaromatic compounds formed from thermal treatment or artificial maturation of coals may be artifacts.

(b) Simulation experiments with fatty acids in the presence of bentonite and elemental sulphur

Additional artificial maturation experiments were performed in the presence of bentonite and elemental sulphur to determine whether or not high molecular weight organic sulphur compounds (OSC) could be produced under such conditions. The HTGC of the products obtained from the maturation of C16/S/bentonite in Fig. 4 with the major compound in the chromatogram being $n-\mathrm{C}_{15}$, produced in much higher relative concentrations than in the absence of elemental sulphur. The relative proportions of the various fractions from the experiments with the $C_{16}$ fatty acid and sulphur, with and without bentonite, 


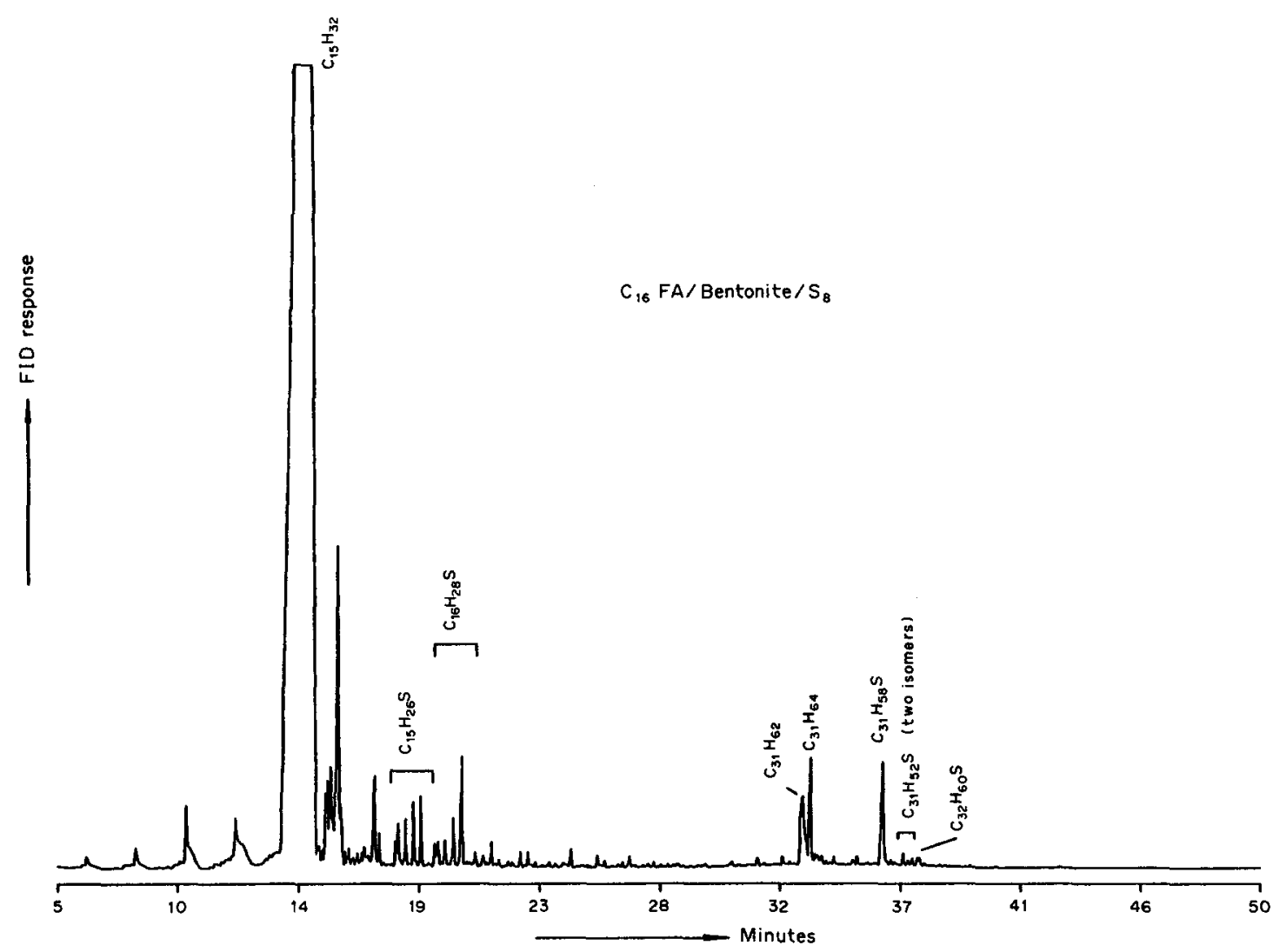

Fig. 4. FID HTGC of the saturate fraction isolated from the simulation experiment using the $\mathrm{C}_{16}$ fatty acid in the presence of bentonite and elemental sulphur.

are given in Table 1. No fatty acids were recovered in these experiments. Two polar fractions were eluted, one with $\mathrm{CH}_{2} \mathrm{Cl}_{2}$ and one with $\mathrm{CH}_{2} \mathrm{Cl}_{2} / \mathrm{MeOH}$ respectively. Furthermore it should be noted that in the presence of elemental sulphur alone, a polymer-like material was formed in a $3 \%$ yield but could not be quantitated in the presence of bentonite due to adsorption with the bentonite. The higher yield of the $n-C_{15}$ suggests that the elemental sulphur may be acting as a catalyst for the decarboxylation of the fatty acids leading to the preferential formation of the alkanes. Minor amounts of $n$-alkanes were also found in the $\mathrm{C}_{11}-\mathrm{C}_{17}$ range and the cyclic compounds in the low molecular weight region were found to be the same as those produced in the absence of elemental sulphur (i.e. $\mathrm{C}_{16} n$-alkylcyclohexane and methyl, $n$-alkylcyclohexanes).

Several series of organic sulphur compounds possessing a linear carbon skeleton [mainly 2,5-dialkylthiophenes and 2,4-di- $n$-alkylbenzo(b)thiophenes] were identified in the products from the maturation experiments. Series of organic sulphur compounds with a linear carbon skeleton have been identified in oils and sediment extracts, and their use as markers for depositional environments and diagenesis have been discussed (Sinninghe Damste et al., 1987; Kohnen et al., 1990b). It is known that functionalized molecules can incorporate sulphur in sediments during the early stages of diagenesis, presumably by reaction with hydrogen sulphide (or related species), elemental sulphur, or polysulphides, all abundantly produced directly or indirectly by bacterial processes in anoxic environments. However the experiments described herein clearly show that these OSC compounds may also form at the later stages of diagenesis and slightly higher temperatures.

Series of 2- $n$-alkyl and 2,5-di-n-alkylthiophenes in the range $C_{14}-C_{32}$ were tentatively identified on the basis of mass spectral data and relative retention times (Fig. 5). The most abundant of the alkylthiophenes in the low molecular weight region were the $\mathrm{C}_{15}$ and $\mathrm{C}_{16}$ 2,5-di-n-alkylthiophenes. All positional isomers of 2,5-di-n-alkylthiophenes at a given number of carbon atoms were encountered and in the case of $\mathrm{C}_{16}$, the 2-dodecylthiophene was the most abundant isomer, whereas in the case of $\mathrm{C}_{15}$ thiophenes a more complex mixture of isomers was present. No alkylthiolanes could be detected in these experiments. Schmid et al. (1987) also detected the formation of series of 2,5-dialkylthiophenes and dialkylbenzo(b)thiophenes from the reaction of alkanes and elemental sulphur at temperatures between 200 and $250^{\circ} \mathrm{C}$. Sinninghe Damste et al. (1987) suggested that unsaturated fatty acids or alcohols could also play a role as precursors for the series of OSC with linear carbon skeleton. 


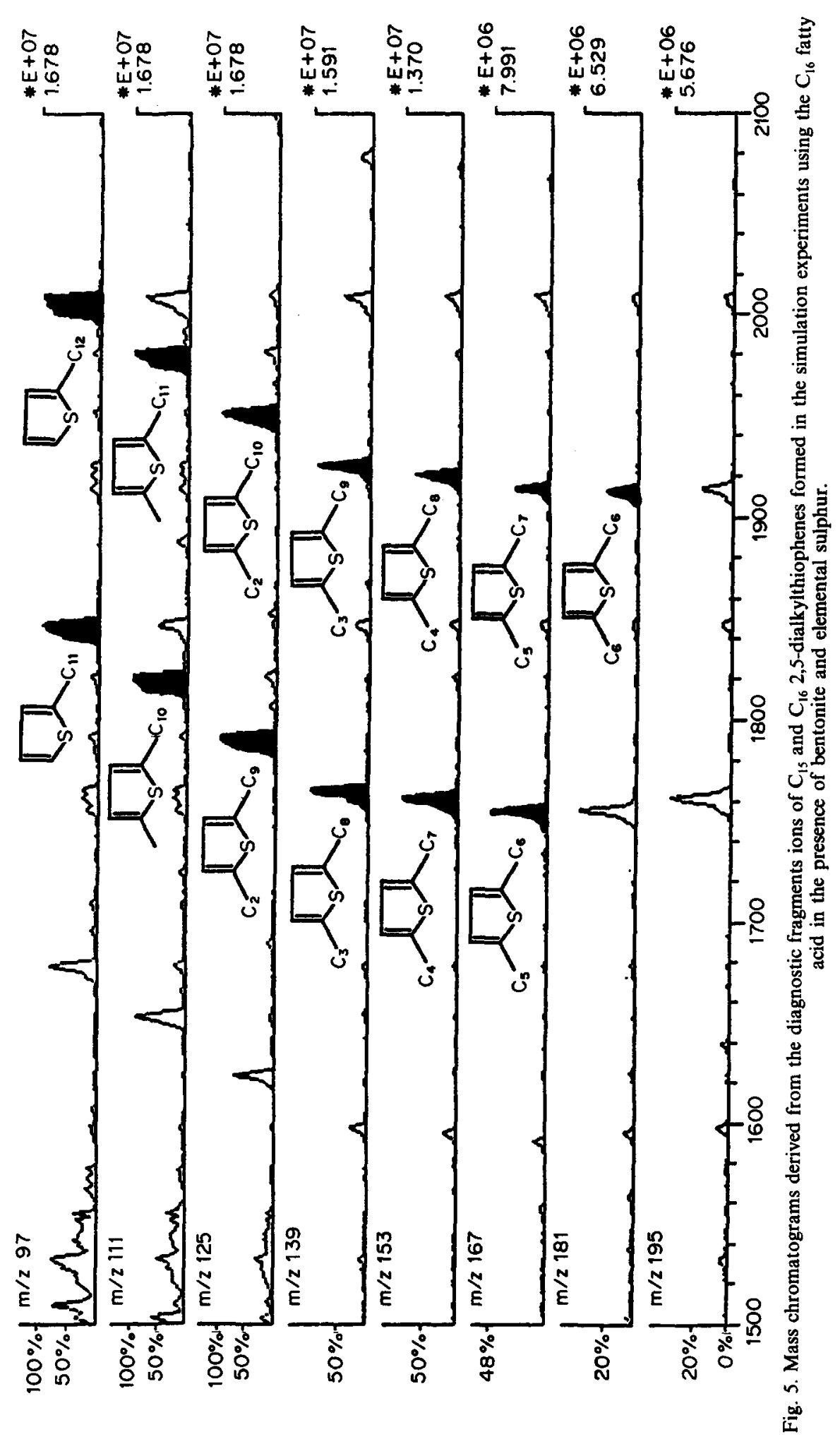


The major high molecular weight components from these experiments were dimerization products, typically with 31 carbon atoms, with no trimerization products being detected in any of the experiments. The $C_{31}$ hydrocarbons produced were the same as those in the experiments performed in the absence of elemental sulphur and dominated by alkanes, cycloalkanes, and aromatic hydrocarbons. Dialkylthiophenes and dialkylbenzo(b)thiophenes were the main structures found among the $\mathrm{C}_{31} \mathrm{OSC}$. The absence of trimerization products in these experiments may be related to high sulphur content leading to preferential formation of the $\mathrm{C}_{15}$ alkane via a decarboxylation mechanism along intramolecular incorporation of sulphur and subsequent cyclization.

The mass spectrum of the $\mathrm{C}_{31}$ dialkylthiophene was characterized by a molecular ion at $m / z 462$ and characteristic fragment ions resulting from $\beta$ cleavages of the alkyl substituents at $m / z 265$ and 307 [Fig. 6(a)]. An averaged mass spectrum for the peak produced by this component in the chromatogram reveals that the peak is dominated by one structural isomer, tentatively identified from the mass spectral data as 2-dodecyl-5-pentadecylthiophene. Possible mechanisms for the formation of the $\mathrm{C}_{31}$ dialkylthiophene include intramolecular incorporation of sulphur into $C_{31}$ acyclic compounds, or incorporation of sulphur on an intermolecular basis using $\mathrm{C}_{15}$ and $\mathrm{C}_{16}$ moieties followed by cyclization. Minor amounts of a $_{32}$ dialkylthiophene, with molecular ion at $m / z 476$ and characteristic peaks at $m / z 265$ and 321 in its mass spectrum, were also detected, and identified as 2-dodecyl-5-hexadecylthiophene. The high molecular weight 3,4-di- $n$-alkylthiophenes recently identified by Kohnen et al. (1990a) in immature sediments could not be detected in these experiments. The proposed hypothetical precursors for these compounds should have a mid-chain dimethyl branched alkane skeleton. Kohnen et al. (1990a) proposed that formation of these compounds via dimerization of functionalized lipids seemed to be unlikely since such random dimerization reactions would lead to complex mixtures of structural isomers for each number of carbon atoms, a phenomenon not observed in the naturally occurring 3,4-di- $n$-alkylthiophenes assemblage. However, random dimerization reactions were not observed to occur in our experiments since the products were dominated by one structural isomer at each carbon number in the high molecular weight region $\left(C_{30}, C_{31}, C_{32}\right)$. Therefore, we suggest that with the appropriate monomer precursors it may be possible to form a dimerization product with a carbon skeleton that would incorporate sulphur and lead to the formation of 3,4-di- $n$-alkylthiophenes. Alternatively the 3,4-di- $n$-alkylthiophenes could form by rearrangement of the 2,5-di- $n$-alkylthiophenes.

Two $C_{31}$ di- $n$-alkylbenzo(b)thiophenes structural isomers were tentatively identified in the products of the simulation experiments on the basis of their mass spectral data [Fig. 6(b) and (c)]. The spectra are characterized by molecular ions, ions resulting from $\beta$-cleavages of the alkyl side chains and ions resulting from a McLafferty rearrangement (Sinninghe Damste et al., 1987). The compounds were tentatively identified as 2-pentadecyl-4-octadecylbenzo(b)thiophene and 2-dodecyl-4-undecylbenzo(b)thiophene with characteristic ions at $m / z 260$ and 302 respectively, resulting from the McLafferty rearrangement. The 2,4-di- $n$-alkylbenzothiophenes can be formed from the structurally related 2,5-di- $n$-alkylthiophenes via ring closure followed by aromatization as suggested by Perakis (1986), Sinninghe Damste et al., (1987), and Schmid (1986). Our results also suggest that dialkylbenzo(b)thiophenes have been formed from such a mechanism, since both of the $C_{31}$ 2,4di- $n$-alkylbenzo(b)thiophenes could form by the cyclization of the alkyl side chains of 2-dodecyl-5pentadecylthiophene.

Series of bithiophenes and thienyl thiolanes were detected in the low molecular weight region of the aromatic fraction from $\mathrm{C}_{10}$ to $\mathrm{C}_{16}$ and were dominated by the $\mathrm{C}_{15}$ homologues. The presence of two sulphur atoms per molecule was proposed on the basis of the much higher FPD response relative to compounds containing one sulphur atom and from their mass spectra. No oligomerization compounds with these structures were detected.

A dimerization product was isolated from the 'aromatic' fraction of the maturation experiments that were performed in the presence of sulphur and bentonite as well as the fatty acids. No sulphur was present in this component as indicated by the absence of any FPD response. Interpretation of the mass spectral data [Fig. 6(d)] suggested a $\mathrm{C}_{31}$ linear skeleton, no branching, and the presence of a mid-chain carbonyl group leading to its tentative identification as 16-hentriocontanone. Mid-chain ketones have been previously reported in a number of marine and lacustrine sediments (Boon and de Leeuw, 1979; Cranwell, 1984). Their origin and significance remains rather unclear although Cranwell (1984) suggested that the ketones were unlikely to form by in situ oxidation of alkanes and could originate from cuticular plant wax components. Aizenshtat et al. (1984) noted that heating carboxylic acids in the presence of clay minerals, may lead to the formation of anhydrides which, can undergo decarboxylation to form mid-chain ketones. Our results also suggest that the mid-chain ketones might have diagenetic origin from fatty acids. A diagenetic relationship between the mid-chain ketones and the 1,15-diols and 15-ketoalkan-1-ols isolated from a number of sediments (de Leeuw et al., 1981) is likely although the 1,15-diols and 15-keto-alkan-1-ols are known to have a biological origin (Morris and Brassell, 1988; Volkman et al., 1992).

The origin of high molecular weight hydrocarbons and organic sulphur compounds (above $\mathrm{C}_{40}$ ) recently detected in geological materials (Carlson et al., 1989; Kohnen et al., 1990a; Del Rio and Philp, 1992a) is 


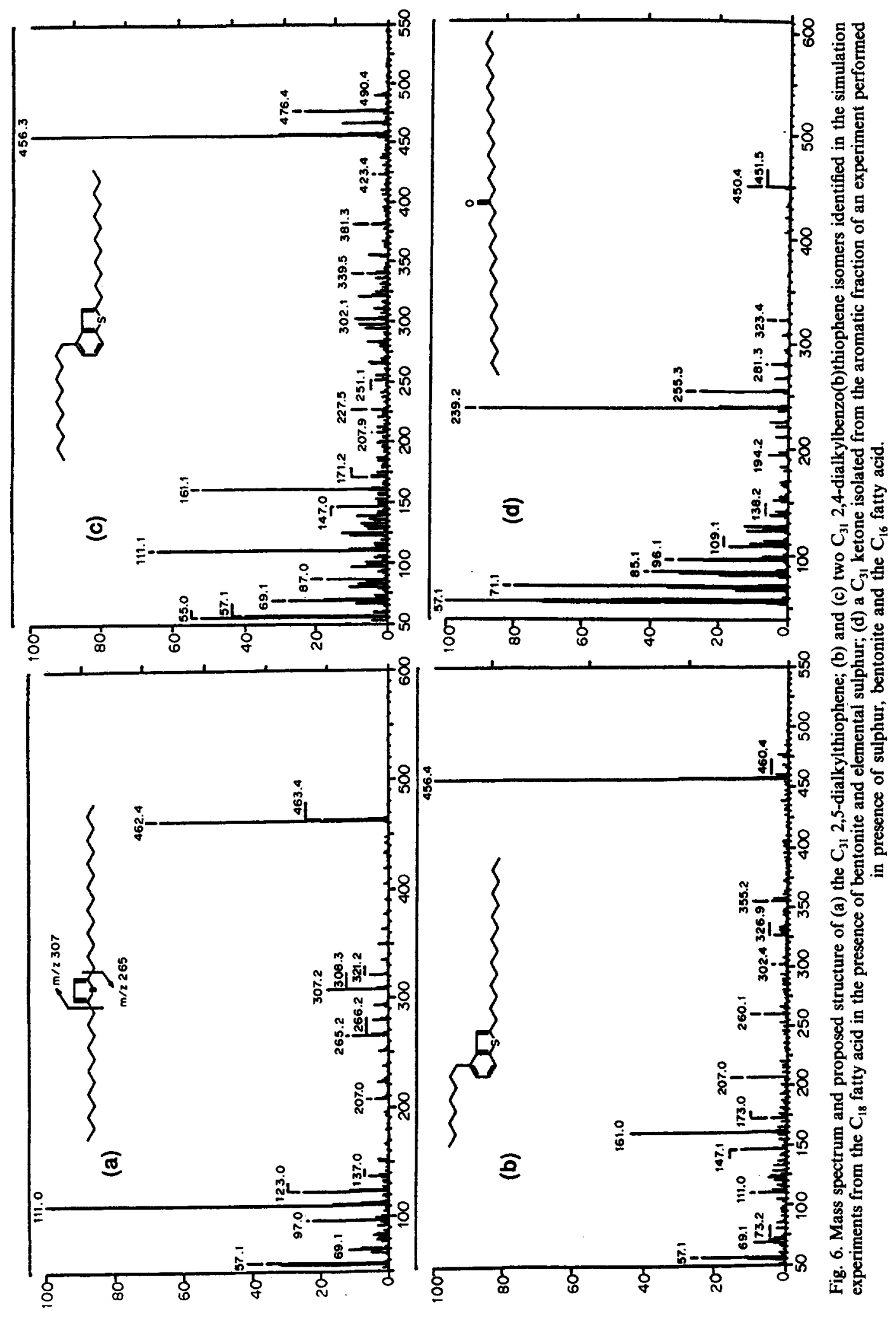


still not clearly understood. However our results have shown that under the conditions used in these simulation experiments, naturally occurring long-chain fatty acids can serve as suitable precursors for high molecular weight hydrocarbons via oligomerization processes. The relatively high concentrations of oligomers produced in the simulation experiments is a reflection on the concentration of monomers used in the experiments. In the natural situation lower concentrations of the monomers in the sediments will lead to relatively low concentrations of the oligomers (de Leeuw et al., 1980). However, due to the low volatility, and solubility, and hence low mobility of the high molecular weight compounds, they will be concentrated under certain conditions such as in oil pipelines (Del Rio and Philp, 1992a) or they may be incorporated either trapped or chemically bound into the kerogen and asphaltene fractions.

Oligomerization of fatty acids is not the only possible method for formation of high molecular weight compounds. De Leeuw et al., (1980) obtained di- and trimerization products in maturation experiments with phytol and an aromatic dimer of phytol in a marine sediment sample extract. Van Aarssen and de Leeuw (1989), identified some $C_{30}$ bicadinane and $\mathrm{C}_{45}$ tricadinane compounds thought to be di- and trimerization products of cadinane monomers and pointed out that under appropriate conditions sesquiterpenoids may dimerize or oligomerize via an abiotic mechanism. Therefore, we suggest that organic compounds with appropriate functional groups such as carboxyl and hydroxyl groups under the appropriate conditions may oligomerize to form high molecular weight compounds although clearly more work involving maturation in simulation experiments with different classes of naturally occurring products are needed to evaluate this hypothesis in more detail. The emphasis in this paper has been directed at possible oligomerization mechanisms but it should be emphasized that the possibility of these compounds coming from naturally occurring functionalized molecules certainly cannot be excluded on the basis of experiments performed herein. Until now, very little has been known about the structures of high molecular weight compounds present in geological materials, but with the development of the new high temperature columns and supercritical fluid chromatography (SFC) technique, it is anticipated that a number of new high molecular weight structures will be discovered.

\section{CONCLUSIONS}

The experiments described in this paper have shown that naturally occurring long chain fatty acids are possible precursors of some naturally occurring high molecular weight hydrocarbons and organosulphur compounds produced through an oligomerization processes. In the presence of bentonite $30-40 \%$ of the original fatty acid was converted to dimers and trimers. Mixtures of fatty acids heated with bentonite would produce complex mixtures of saturate hydrocarbons. The presence of elemental sulphur inhibits the formation of these compounds leading instead to decarboxylation products precluding the formation of oligomers. The presence of elemental sulphur in these maturation experiments leads to the formation of series of 2,5-dialkylthiophenes and 2,4-di- $n$-alkylbenzo(b)thiophenes. Hence in summary, despite the somewhat facile nature of these experiments, it has been demonstrated that fatty acids can oligomerize to form high molecular weight hydrocarbons, similar to those recently observed in several crude oils and may represent one mechanism by which these compounds are formed in the sedimentary environment.

Acknowledgements-We wish to thank A. Galvez-Sinibaldi for his technical assistance in the DIP-MS analyses. This work was supported by NSF grant \#EAR-9118133.

\section{REFERENCES}

van Aarssen and de Leeuw J. W. (1989) On the identification and occurrence of oligomerized sesquiterpenoid compounds in oils and sediments of South East Asia. 14th International Meeting on Organic Geochemistry. Abstracts, Paris, France, 18-22 September 1989. (Abstract only).

Aizenshtat Z., Miloslavsky I. and Heller-Kallai L. (1984) The effect of montmorillonite on the thermal decomposition of fatty acids under "bulk flow" conditions. Org. Geochem. 1, 85-90.

Albaiges J. (1980) Identification and geochemical significance of long chain acyclic isoprenoid hydrocarbons in crude oils. In Advances in Organic Geochemistry 1979, (Edited by A. G. Douglas and J. R. Maxwell), pp. 19-28. Pergamon Press, Oxford.

Boon J. J. and de Leeuw J. W. (1979) The analysis of wax esters, very long mid-chain ketones and sterol ethers isolated from Walvis Bay diatomaceous ooze. Mar. Chem. 7, 117-132.

Carlson R. M. K., Moldowan J. M., Gallegos J. M., Peters K. E., Seetoo W. C. and Smith K. S. (1989) Proc. 14th International Meeting on Organic Geochemistry, Paris, France, 18-22 September. (Abstract only).

Chojnacki T., Swiezewska E. and Vogtman T. (1987) Polyprenols from plants-structural analogues of mammalian dolichols. Chem. Scripta 27, 209-214.

Cranwell P. A. (1984) Alkyl esters, mid chain ketones and fatty acids in late glacial and postglacial lacustrine sediments. Org. Geochem. 6, 115-124.

Del Rio J. C., Philp R. P. and Allen J. (1992a) Nature and geochemistry of high molecular weight hydrocarbons (above $\mathrm{C}_{40}$ ) in oils and solid bitumens. Org. Geochem. 18, $541-553$.

Del Rio J. C. and Philp R. P. (1992b) High molecular weight hydrocarbons: a new frontier in Organic Geochemistry. Submitted to Trends Anal. Chem. 11(5), 187-193.

Johns W. D. (1979) Clay minerals catalysis and petroleum generation. Ann. Rev. Earth Planet. Sci. 7, 183-198.

Kohnen M. E. L., Peakman T. M., Sinninghe Damste J. S. and de Leeuw J. W. (1990a) Identification and occurrence of novel $\mathrm{C}_{36}-\mathrm{C}_{54}$ 3,4-dialkylthiophenes with an unusual carbon skeleton in immature sediments. Org. Geochem. 164, 1103-1113.

Kohnen M. E. L., Sinninghe Damste J.S., Rijpstra W. I. C. and de Leeuw J. W. (1990b) Alkylthiophenes as sensitive indicators of paleoenvironmental changes - a study of the Cretaceous Oil Shale from Jordan. In Geochemistry of Sulfur in Fossil Fuels (Edited by Orr W. L. and White 
C. M.), Chap. 25, pp. 444-485. ACS Symposium series, American Chemical Society, Washington, D.C.

de Leeuw J. W., Rijpstra W. I. C. and Schenck P. A. (1981)

The occurrence and identification of $C_{30}, C_{31}$ and $C_{32}$ alkan-1,15-diols and alkan-15-on-1-ols in Unit I and Unit II Black Sea sediments. Geochim. Cosmochim. Acta 45, 2281-2285.

de Leeuw J. W., Simoneit B. R. T., Boon J. J., Rijpistra W.

I. C., Delange F., Leeden J. C. W., Correia V. A., Burlingame A. L. and Schenck P. A. (1980) Phytol derived compounds in the geosphere. In Advances in Organic Geochemistry 1979 (Edited by A. G. Douglas and J. R. Maxwell), pp. 211-217. Pergamon Press, Oxford.

Liacen-Jensenn S. (1990) Marine carotenoids-selected topics. New J. Chem. 14, 747-759.

Moldowan J. M., Seifert W. K. and Gallegos E. J. (1983) Identification of extended series of tricyclic terpanes in petroleum. Geochim. Cosmochim. Acta 47, 1531-1534.

Morris R. J. and Brassell S. C. (1988) Long-chain alkanediols: Biological markers for cyanobacterial contributions to sediments. Lipids 23, 256-258.

Perakis N. (1986) Separation et detection selective des composes sufrés dans les fractions lourdes des petroles. Geochemie des benzo(b)thiophenes. Ph.D. dissertation, University of Strasbourg.

Radke M., Willsch H., Leythaeuser D. and Teichmuller M. (1982) Aromatic components of coal: relation of distribution pattern to rank. Geochim. Cosmochim. Acta 46, 1831-1848.

Rigby D., Gilbert T. D. and Smith J. W. (1986) The synthesis of alkyl aromatic hydrocarbons and its geochemical implications. Org. Geochem. 9, 255-264.
Rubinstein I. and Strausz O. P. (1979) Geochemistry of the thiourea adduct fraction from an Alberta petroleum. Geochim. Cosmochim. Acta 43, 1387-1392.

Schmid J. C. (1986) Marqueurs biologiques soufrés dans les pétroles. Ph.D. dissertation. University of Strasbourg.

Schmid J. C., Connan J. and Albrecht P. (1987) Oocurrence and geochemical significance of long-chain dialkylthiacyclopentanes. Nature 329, 54-56.

Sinninghe Damsté J. S., de Leeuw J. W., Kock-van Dale A. C., de Zeeuw M. A., de Lange F., Rijpstra W. I. C. and Schenck P. A. (1987) The occurrence and identification of a series of organic sulphur compounds in oils and sediment extracts. I. A study of Rozel Point Oil (U.S.A.). Geochim. Cosmochim. Acta 51, 2369-2391.

Suga T., Ohta S., Nakai A. and Munesada K. (1989) Glyciniprenols: novel polyprenols possessing a phytol residue from the leaves of soybean. J. Org. Chem. 54, 3390-3393.

Swiezewska E. and Chojnacki T. (1988) Long chain polyprenols in gymnosperm plants. Act Biochim. Polonica 35, 131-147.

Swiezewska E. and Chojnacki T. (1989) The occurrence of unique, long chain polyprenols in the leaves of Potentilla species. Acta Biochim. Polonica 36, 143-158.

Volkman J. K., Barrett S. M., Dunstan G. A. and Jeffrey S. W. (1992) $C_{30}-C_{32}$ alkyl diols and unsaturated alcohols in microalgae of the class Eustigmatophyceae. Org. Geochem. 18, 131-138.

Williams J. A., Dolcater D. L., Torkelson B. E. and Winters J. C. (1988) Anomalous concentrations of specific alkylaromatic and alkylcycloparaffin components in West Texas and Michigan crude oils. Org. Geochem. 13, 47-59. 